Thornes, JE; Randalls, S; (2014) Applied meteorology and climatology. Progress in

Physical Geography , 38 (4) 389 - 391. 10.1177/0309133314539234. Downloaded from

UCL Discovery: http://discovery.ucl.ac.uk/1455197/

\title{
ARTICLE
}

\section{Applied Meteorology and Climatology}

\author{
John E. Thornes, School of Geography, Earth and Environmental Sciences \\ University of Birmingham, Edgbaston, Birmingham, B15 2TT \\ j.e.thornes@bham.ac.uk
}

Samuel Randalls, Department of Geography, University College London

Gower Street, London, WC1E 6BT

s.randalls@ucl.ac.uk

The relationship between geographers and study of the atmosphere has not always been straightforward. Lingering concerns about climatic determinism, especially as espoused by Ellsworth Huntington in the early $20^{\text {th }}$ century, haunted the attempts of social scientists interested in the effects of climate on society (Rayner, 2003), while at the same time, physicists took the lead in meteorology leaving physical geographers with the perceived unscientific and rigour-lacking climatology (Koelsch, 1996). Writing in 1965 in Transactions of the Institute of British Geographers, Crowe (1965: 1) argued that, within geography, climatology's “... devoted adherents are few and forward progress during the last Brückner cycle has not been noteworthy. Indeed, it could be said that climatologists have abandoned their cycles before equipping themselves with an attractive bandwagon..." How rapidly this was to shift in the context of emerging interest in global climatic changes from the 1970s onwards!

Despite the arguably limited quantity, geographers and other social scientists had explored many interesting questions about weather, climate and society. For example, urban climatologists, like Tony Chandler, explored the design of urban spaces and their influence on local climatic patterns, a field that has been somewhat sidelined in the rush to ascribe causal power to global rather than local climatic changes (Janković and Hebbert, 2012), though of course exceptions exist especially as related to air pollution. In the 1960s and early 1970s there was a spate of influential applied climatology/climatology text books and edited volumes from climatologists such as John Griffiths (1966), Roger Barry and Richard Chorley (1968), James Taylor (1970; 1972; 1974), David Gates (1972), John Oliver (1973), John Mather (1974), Tim Oke (1978) and John Hobbs (1980). One of the key academic papers at this time was by Werner Terjung (1976) who envisaged a new form of geographical climatology, operationalized through systems theory, to combine both physical and human geography approaches to solve real world problems. Outside of geography, John Maunder (1970; 1989) explored climatic resources and their value for and impact on economic activity and Mikhail Budyko (1974) published the seminal Climate and Life. These texts, advanced in the 1960s and 1970s, developed an atmospheric resource and hazard approach showing that these relations were rarely simple, but had important consequences for weather-sensitive industries. Indeed, far-sighted companies could improve their economic value with strategic responses to weather forecasts. By 1980 Jesse Ausubel 
identified what he called an 'atmospheric sector' that he suggested should provoke economic, ethical and political consideration of the atmosphere's governance, particularly given global pollution threats and changing environmental cycles.

These traditions of applied meteorology and climatology were crystallized through the development of the MSc in this field at the University of Birmingham in 1963, a date that was a key factor in the development of this special section to also commemorate the $50^{\text {th }}$ anniversary of that programme. The MSc was established through the influence of Linton (Head of the Geography Department) and Ted Stringer, who believed that a quantitative climatology was a truly scientific discipline, an important argument given the context of the quantitative revolution then well underway in geography. ${ }^{1}$ At the same time, the MSc was also to provide relevant expertise for society, particularly through the statistical analysis of climate data. While Ted Stringer had his solar panel business in the 1970s, this desire to use weather and climate data and forecasts for societal goods was perhaps best reflected in the establishment of a couple of successful University spin-out companies: Thermal Mapping International (TMI) and Entice Technology Ltd, offering road ice measurement and forecasting services.

Despite this enthusiasm, applied meteorology and climatology has never become a mainstream interdisciplinary field within geography as much as earlier proponents might have hoped. Most geography departments had only one or two climatologists and when, in more recent times, especially in the UK, departments had to form research groups, very few could establish a climatology research group with such small numbers. This led to many climatology posts being lost as climatology teaching and research was covered by other physical geographers. The emergence of global climate change, however, has led many physical geographers to move into climate and society research, and climate change research groups have developed that are often quite 'applied climatology' in composition. The emergence of cultural climatology (Thornes and McGregor 2003) also reflected the mixed composition of such new research groups containing both physical and human geographers as Terjung (1976) had predicted.

This special section highlights the value of those earlier applied traditions, but at the same time suggest that they have significance and importance in understanding climate change debates too. As Hebbert and Jankovic (2013) show, these older approaches can sometimes be re-used for exploring less well-appreciated aspects of climate changes that matter in society today like changing urban forms and corresponding urban heat islands that will only be exacerbated under future temperature increases. Likewise the increasing commercial values placed on the atmosphere are being re-translated into new forms of weather and climate related finance (Thornes and Randalls, 2007), including the emergence of atmospheric or climate services drawing from the ecosystem valuation literatures (Thornes et al., 2010).

The papers in this special section explore both historical and contemporary approaches to applied meteorology and climatology. Tadaki et al. set out the basic ideas and debates of applied climatology, placing the field in its historical context and then demonstrating its contemporary practices and philosophical questions. This provides an overall framing that connects human and physical geography. The rest of the papers focus on more specific issues. Kendall et al. outline the possibility of an atmospheric economic sector producing an inventory through which economists and policymakers can assess and value twelve atmospheric services. Jaroszewski et al. highlight the interdisciplinary tools needed to understand the potential impacts of climate change on transportation demonstrating the value of probabilistic projections and behavioural studies in moving away from singular,

\footnotetext{
${ }^{1}$ With thanks to Brian Giles (2014) for this information, which he has just published for the Royal Meteorological Society's History Group.
} 
universal, deterministic assessments. Finally, Zhang et al. demonstrate the value of a technical focus on urban climatology that is relevant to societal and health problems. They develop a model that leads to an understanding of the relationship between air and surface urban heat islands that could lead to a methodology that allows the spatial patterns of urban heat islands to be derived just from satellite measurements.

Our aim for the issue is to look forward to the ways in which geographers, combining interests from both 'sides' of the discipline, can contribute meaningfully and effectively to contemporary debates on climate change, while not forgetting the applied traditions that made climate and society such an interesting area of research for geographers in the past. It stands as a reminder that there are many ways in which we interact with weather and climate in everyday life, logistical decisions about production, consumption and transportation, health, insurance and so on, which prove that weather and climate have significant value to society at local and regional as much as global scales.

\section{References}

Ausubel J (1980) Economics in the Air - An Introduction to Economic Issues of the Atmosphere. In: Ausubel J and Biswas AK (eds) Climatic Constraints and Human Activities. Oxford: Pergamon Press, 13-59.

Barry RG and Chorley RJ (1968) Atmosphere, Weather and Climate. London: Methuen

Budyko MI (1974) Climate and Life. Waltham: Academic Press, 508 pp.

Crowe PR (1965) The Geographer and the Atmosphere, Transactions of the Institute of British Geographers 36: 1-19.

Gates DM (1972) Man and his Environment: Climate. New York: Harper and Row, 175 pp.

Giles B (2014) MSc in Applied Meteorology and Climatology, University of

Birmingham, 1963-2013.Royal Meteorological Society History Group, Newsletter No.1 2014 